\title{
MENSURAÇÃO DA QUALIDADE DE SERVIÇO NO VAREJO ELETRÔNICO E SEU IMPACTO SOBRE AS INTENÇÕES COMPORTAMENTAIS
}

THE MEASUREMENT OF SERVICE QUALITY IN THE ELECTRONIC RETAIL AND ITS IMPACT ON BEHAVIORAL INTENTIONS

MENSURACIÓN DE LA CALIDAD DE SERVICIO EN EL COMERCIO MINORISTA ELECTRÓNICO Y SU IMPACTO SOBRE LAS INTENCIONES COMPORTAMENTALES

\section{RESUMO}

O construto qualidade de serviços tem sido amplamente pesquisado na literatura de Marketing em termos de antecedentes, consequentes, dimensões, e mensurações. No entanto, há uma carência na realização não somente de pesquisas sobre a qualidade dos serviços em varejo eletrônico, como também sobre a definição e a dimensionalidade do construto nesse ambiente. Sob esse pretexto, o trabalho buscou compreender mais a fundo o construto qualidade percebida no varejo eletrônico. Especificamente, este artigo teve por objetivo verificar empiricamente a estrutura da e-S-Qual no varejo eletrônico. Em termos de método, a amostra continha apenas pessoas que já compraram produtos/serviços no varejo eletrônico, sendo configurada como uma survey do tipo bola de neve por conveniência, perfazendo um total de 515 pessoas.

PALAVRAS-CHAVE Qualidade de serviço, comércio eletrônico, varejo, lealdade, confiança.

Valter Afonso Vieira valterafonsovieira@yahoo.com

Professor do Departamento de Administração Geral e Aplicada, Universidade Federal do Paraná - Curitiba - PR, Brasil

Recebido em 18.12.2007. Aprovado em 05.02.2010

Avaliado pelo sistema double blind review. Editor Científico: Delane Botelho

\begin{abstract}
The service quality construct has been thoroughly researched in the Marketing literature in terms of antecedents, consequents, and dimensions. However, research in electronic service quality lacks accomplishments, as do some definitions and dimensionality tests. In such a context, this paper analyzes the perceived service quality in the electronic retail and correlates it with three marketing constructs. The sample contains people who already had bought services in electronic retailing; a snow-ball survey sample with 515 people was conducted. Results demonstrate that service quality is represented by fulfillment, privacy, system available and efficiency. From the four service quality dimensions, the privacy factor had major impact on loyalty, commitment and trust. The other dimensions were also positively associated.

KEYWORDS Service quality, retail, e-commerce, trust, loyalty.

RESUMEN El constructo 'calidad de servicios' ha sido ampliamente investigado en la literatura de Marketing en términos de antecedentes, consecuentes, dimensiones y mensuraciones. No obstante, existe una carencia en la realización no solo de investigaciones sobre la calidad de los servicios en el comercio minorista electrónico, sino también sobre la definición y la dimensionalidad del constructo en ese ambiente. Por ello, el trabajo buscó comprender más a fondo el constructo calidad percibida en el comercio minorista electrónico. Específicamente, este artículo tuvo como objetivo principal verificar empíricamente la estructura de la e-SQ (e-calidad de servicio) en el comercio minorista electrónico brasileño. En términos de método, la muestra contenía solo personas que ya compraron productos/servicios en el comercio minorista electrónico, siendo configurada como una survey del tipo bola de nieve por conveniencia, totalizando 515 personas.
\end{abstract}

PALABRAS CLAVE Calidad de servicio, comercio electrónico, comercio minorista, lealtad, confianza. 


\section{INTRODUÇÃo}

O amplo desenvolvimento do comércio eletrônico nos últimos anos sugere que as empresas de varejo necessitam um diferencial significativo para atrair e manter consumidores dentro da cadeia, uma vez que os custos de mudanças são menores na internet quando comparados aos canais convencionais (HERNANDEZ, 2002). A necessidade desse desenvolvimento é justificada pelo elevado aumento das vendas no varejo eletrônico. O Gráfico 1 apresenta o crescente faturamento anual do varejo brasileiro em bilhões de reais, sendo que em 2008 ele ultrapassou $\mathrm{R} \$ 8$ bilhões. De acordo com os dados, as vendas no varejo eletrônico vêm subindo ano a ano.

Uma particularidade para o desenvolvimento do comércio eletrônico é a verificação da qualidade dos serviços prestados pelos lojistas. Em termos gerenciais, é essencial as organizações entenderem como os clientes avaliam a qualidade de uma compra on-line, quais fatores são mais proeminentes para o site e quais são as repercussões da qualidade sobre as intenções de compras futuras. Assim, um maior conhecimento dessas características pode gerar maiores chances de sucesso nas vendas no ambiente virtual.

Apesar da relevância da qualidade dos serviços na conjuntura de compras on-line, há uma escassez de pesquisas sobre qualidade de serviços em varejo eletrônico no Brasil.
De caráter similar, é limitada a definição do construto nesse mesmo ambiente. Gummerus e outros (2004) realçam tal situação de escassez e explanam que existe uma deficiência teórica no desenvolvimento da qualidade eletrônica na internet, em termos de antecedentes, consequentes, dimensões e mensurações.

Sendo mais específico, se o quesito mensuração da qualidade for tomado de modo isolado, é verdade que tem havido contribuições para o ambiente convencional desde os trabalhos seminais de Parasuraman, Zeithaml e Berry (1985 e 1988), de Parasuraman, Berry e Zeithaml (1991) e de Cronin e Taylor (1992 e 1994) com a proposta da ServQual e da ServPerf. Todavia, contribuições para o ambiente virtual sobre a medição da qualidade de serviços ainda são necessárias, especificamente no campo do varejo eletrônico, uma vez que as medidas tradicionais possuem um viés de ambiente.

Em virtude da relevância gerencial do tema e do seu incipiente avanço na atmosfera eletrônica, este trabalho busca (a) verificar a escala de qualidade eletrônica e-S-Qual, de Parasuraman, Zeithaml e Malhotra (2005), e (b) testar um modelo que avalie as relações entre qualidade percebida pelo cliente do varejo virtual e comprometimento, lealdade e confiança. Em termos gerenciais, o modelo pretende responder às seguintes questões: (1) Existe efeito diferente de cada componente de qualida-

\section{Gráfico 1 - Faturamento anual do varejo em bilhões de R\$}

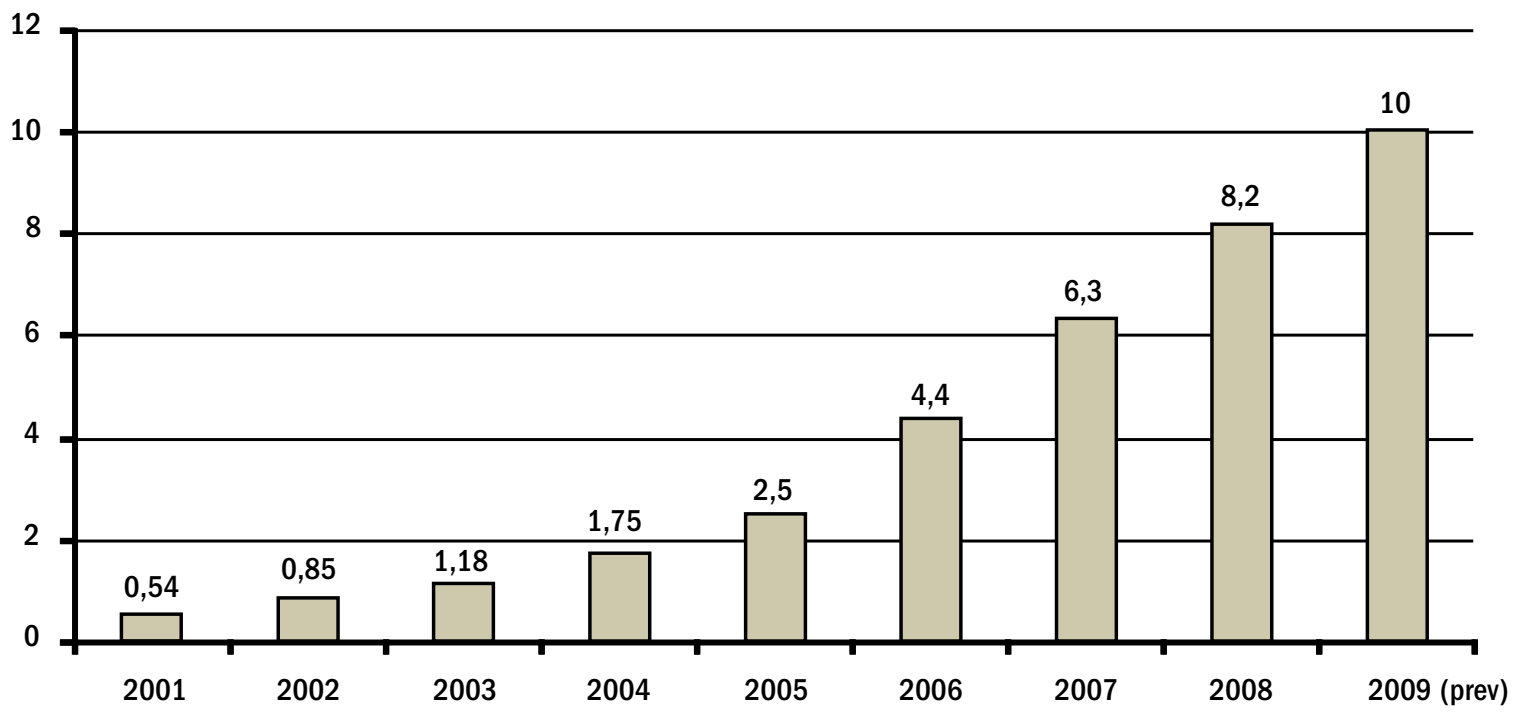

Fonte: Levantamento realizado pela empresa e-Bit www.ebitempresa.com.br; compilação: www.e-commerce.org.br; eixo $Y=$ bilhões de reais; eixo $X=$ ano; não considera as vendas de automóveis, passagens aéreas e leilões on-line. 
de sobre a confiança e a intenção de retorno do cliente? (2) Quais aspectos da qualidade são mais relevantes no contexto de compra virtual? (3) O instrumento e-S-Qual possui confiabilidade e é multidimensional?

\section{Qualidade percebida}

Para Zeithaml (1987, p. 3), a qualidade percebida pode ser definida como "o julgamento do consumidor sobre a excelência ou superioridade global de um produto". Essa avaliação geral tem como base de formação a 'teoria do paradigma da desconformidade' (PARASURAMAN, ZEITHAML e BERRY, 1985; PARASURAMAN e GREWAL, 2000). Nota-se que essa base não é uma referência amplamente aceita (MARCHETTI e PRADO, 2001), sendo, por vezes, até mesmo criticada pela literatura (CRONIN e TAYLOR, 1992 e 1994), pois toma como base a comparação das expectativas dos consumidores sobre o desempenho percebido do produto (PARASURAMAN, ZEITHAML E MALHOTRA, 2005; PARASURAMAN, ZEITHAML e BERRY, 1985, MARCHETTI e PRADO, 2001). Observa-se que a definição de qualidade de Zeithaml (1987) é amplamente aceita nos estudos convencionais de hoje. Entretanto, uma limitação com as definições de qualidade antes de 1995 é que a internet não estava no seu ponto culminante. Assim, estudos que empregam atualmente a qualidade no varejo eletrônico precisam redefini-la conceitualmente, dado o viés de um ambiente para outro.

Ilustrando um exemplo de viés de ambiente, tem-se o trabalho de Gefen (2002), o qual buscou estender a escala ServQual, criada com base na definição de qualidade física, para o ambiente eletrônico, analisando-a por meio de compras eletrônicas. Os resultados mostraram que as cinco dimensões propostas - tangibilidade, empatia, confiabilidade, capacidade de resposta e segurança - se fundiram em três, sendo elas a tangibilidade, uma dimensão combinada de capacidade de resposta, confiabilidade e segurança, e a empatia. Esse resultado é diferente da estrutura clássica encontrada por Parasuraman, Zeithaml e Berry (1988), e pode ser contra-argumentado. Isso porque a escala que visa mensurar qualidade em serviços no ambiente real não se desenvolveu bem no ambiente virtual, e apresentou uma ordem dimensional confusa. Logo, a crítica à investigação de Gefen (2002) é que o instrumento foi adaptado para verificar a qualidade eletrônica ( $v s$. qualidade tradicional).

Parasuraman, Zeithaml e Malhotra (2005, p. 220), estudando o ambiente eletrônico e utilizando a estrutura teórica da cadeia de meios e fins, "propuseram a escala e-S-Qual para mensurar o desempenho da qualidade do website".
A vantagem deste novo instrumento, diferentemente da proposta de Gefen (2002), é a 'especificidade' para o meio eletrônico. Os autores chegaram a três grandes conclusões: (i) a noção de que a qualidade dos serviços vem de uma comparação do desempenho atual do serviço com a expectativa, (ii) os cinco fatores da qualidade da ServQual (confiabilidade, capacidade de resposta, segurança, empatia e responsabilidade) captam o domínio geral da qualidade dos serviços, e (iii) as avaliações dos consumidores sobre a qualidade do serviço são fortemente ligadas ao valor percebido e às intenções comportamentais.

Devido a essa revisão teórica, Parasuraman, Zeithaml e Malhotra (2005, p. 217) sugerem uma definição para o construto qualidade de serviços em ambientes eletrônicos. Para esses autores, qualidade é "a extensão pela qual o site auxilia, eficiente e efetivamente, a compra e a entrega" do bem. Seguindo a definição conceitual do fenômeno, os pesquisadores partem para uma pesquisa de campo, objetivando a construção de um instrumento para a mensuração da qualidade no ambiente eletrônico. Diante da revisão de literatura, os autores identificaram 11 dimensões de qualidade. Elas são denominadas: confiabilidade, capacidade de resposta, acesso, flexibilidade, facilidade de navegação, eficiência, confiança, segurança/ privacidade, conhecimento do preço, estética e customização/personalização. Após a geração conceitual dos 11 fatores, essas dimensões sugeriram 121 itens, que representam as facetas da qualidade eletrônica. Posteriormente a uma coleta de 549 questionários, Parasuraman, Zeithaml e Malhotra (2005) purificaram a e-S-Qual e reduziram as variáveis para 22, agrupando-as em quatro fatores. Diante dos achados, foi possível concluir que a estrutura final da qualidade no ambiente eletrônico é reflexo de:

- Qualidade de eficiência: facilidade e velocidade de acessar o site.

- Qualidade de disponibilidade do sistema: a funcionalidade correta e técnica do site.

- Qualidade de preenchimento: a extensão na qual o site promete entregar o pedido de modo correto e eficaz, juntamente com a sua disponibilidade.

- Qualidade de privacidade: o grau no qual o site demonstra segurança e sigilo nas informações particulares do consumidor.

Para Parasuraman, Zeithaml e Malhotra (2005), os resultados do modelo estrutural confirmatório obtiveram bons ajustamentos. Um resultado fundamental do trabalho é a análise nomológica feita após os testes de purificação do instrumento. A dimensão qualidade de disponibilidade 
do sistema não foi preditora de valor, lealdade e qualidade geral. Assim, acredita-se que características técnicas e operacionais podem não gerar valor e intenção de recompra. A qualidade de privacidade, por sua vez, foi explicadora apenas do valor (veja a amostra na Amazon.com), dando a entender que aspectos de sigilo de informações dos consumidores podem gerar maiores benefícios para os clientes. Por fim, a qualidade de privacidade não teve impacto significativo sobre a qualidade global e a lealdade. Os resultados gerais podem ser vistos na Tabela 1.

Sintetizando, justifica-se a preferência de utilização da escala e-S-Qual em detrimento de outras pelo fato de que (i) ela foi elaborada exclusivamente para mensurar a qualidade em varejo eletrônico e não foi baseada em sites adversos na internet (ex. entretenimento, institucional, ONGs, governamental etc.), o que poderia ser mais amplo, (ii) o número de itens do instrumento favorece sua opção e (iii) o instrumento passou por um exame de confiabilidade, validade e análise fatorial confirmatória, alcançando excelentes resultados naquele trabalho.

Perante o apresentado, esta investigação busca (a) verificar a escala de qualidade e-S-Qual de Parasuraman, Zeithaml e Malhotra (2005) e (b) testar um modelo que avalie as relações da qualidade percebida. Para tal finalidade, o trabalho está estruturado da seguinte forma. A próxima parte apresenta as relações hipotetizadas de qualidade eletrônica. Após isso, verifica-se o instrumento em uma amostra heterogênea. Dada a constatação de sua validade, na seção de testes das hipóteses verifica-se o desempenho do modelo sugerido.

\section{RELAÇÕES TEÓRICAS PROPOSTAS}

Diante da literatura revisada, duas bases sugerem uma associação entre qualidade e confiança. Inicialmente, Henning-
Thurau e Klee (1997, p. 751), desenvolvendo o argumento de relação entre qualidade e confiança, contextualizam que "a ênfase no processo de 'generalização' requer uma sequência inicial de experiências entre o cliente e a empresa que forneça ao consumidor condições de julgar a confiabilidade do fornecedor. No início da relação entre ambos, a fonte predominante de identificação das experiências é a qualidade geral do serviço prestado, em que o consumidor analisa o desempenho do fornecedor vs. o padrão atual esperado". Uma sequência consistente de experiências positivas criadas, que é a experiência repetida com o fornecedor que mantém a promessa de prover no mínimo o desempenho esperado, pode levar ao desenvolvimento de confiança pelo processo anteriormente descrito de generalização da sequência de experiências para futuras transações (HENNING-THURAU, GWINNER e GREMLER, 2002). Nesse bojo, a qualidade, indicando a superioridade e a certeza do serviço, gera aspectos de confiança no comprador por meio de uma sequência de experiências transacionais positivas entre cliente e empresa. Em segundo plano, Grewal, Monroe e Krishnan (1998, p. 48) salientam que "os 'modelos baseados no valor' pressupõem o ganho 'líquido da compra' como componente principal. Assim, para esses modelos, a aquisição percebida de valor do produto será positivamente influenciada pelos benefícios que os compradores obtiverem. Nesse sentido, um importante elemento no ganho líquido é a qualidade do produto ou a percepção de qualidade que reflete o benefício". Desse modo, a qualidade aumenta o ganho líquido da compra, uma vez que sugere maior valor, e esse ganho líquido tende a criar maior confiança do consumidor no lojista. Tomando como sustentação esses argumentos, as hipóteses criadas são:

$\mathrm{H}_{1 \mathrm{a}}$ : Existe uma relação linear positiva entre qualidade de eficiência e confiança.

$\mathrm{H}_{1 \mathrm{~b}}$ : Existe uma relação linear positiva entre qualidade de sistema e confiança.

Tabela 1 - Análise de regressão das dimensões de qualidade contra valor, qualidade e lealdade

\begin{tabular}{|l|c|c|c|c|c|c|}
\hline \multirow{2}{*}{ DIMENSÕES } & \multicolumn{3}{|c|}{ AMOSTRA AMAZON.COM } & \multicolumn{3}{c|}{ AMOSTRA WALMART } \\
\cline { 2 - 8 } & QUALIDADE & VALOR & LEALDADE & QUALIDADE & VALOR & LEALDADE \\
\hline Eficiência & $0,46^{* *}$ & $0,56^{* *}$ & $0,36^{* *}$ & $0,37^{* *}$ & $0,53^{* *}$ & $0,39 * *$ \\
\hline Disposição Sistema & $-0,03$ & $-0,04$ & 0,03 & $-0,01$ & 0,05 & 0,04 \\
\hline Preenchimento & $0,35^{* *}$ & $0,20^{* *}$ & $0,34 * *$ & $0,46 * *$ & $0,27 * *$ & $0,34^{* *}$ \\
\hline Privacidade & 0,04 & $0,08^{*}$ & 0,04 & $-0,03$ & $-0,03$ & 0,02 \\
\hline$R^{2}$ Ajustado & $57 \%$ & $55 \%$ & $49 \%$ & $56 \%$ & $58 \%$ & $52 \%$ \\
\hline
\end{tabular}

Fonte: Estudo de Parasuraman, Zeithaml e Malhotra (2005).

Nota: $* p<0,05 ; * * p<0,01 ; * * * p<0,001$; dimensões são fatores independentes; qualidade, valor e lealdade são variáveis dependentes. 
$\mathrm{H}_{1 \mathrm{c}}$ : Existe uma relação linear positiva entre qualidade de privacidade e confiança.

$\mathrm{H}_{\mathrm{ld}}$ : Existe uma relação linear positiva entre qualidade de preenchimento e confiança.

Boulding e outros (1993, p.12) propõem a seguinte função para pressupor uma associação entre qualidade e intenções comportamentais (CRONIN, BRADY e HULT, 2000). A fórmula é descrita como BIim $=f 5$ (OSQit), onde "Blimt é igual a mésima intenção comportamental (isto é, lealdade, boca a boca, etc.) para o indivíduo $i$ ao tempo $t$. OSQ é a qualidade do serviço observada. Assim, os autores acreditam que a qualidade do serviço (OSQ) afeta os resultados comportamentais positivamente". De fato, os resultados suportaram a hipótese proposta por Boulding e outros (1993) de qualidade como preditora das intenções. Noutra perspectiva, Cronin e Taylor (1992, p. 59) propõem que "as percepções que o consumidor tem de qualidade afetam suas intenções de compra". Se para Cronin e Taylor (1992) qualidade está relacionada com intenção de compra e se para Oliver (1999) lealdade é um comprometimento em comprar novamente o produto, acredita-se que esses construtos estão diretamente relacionados, uma vez que qualidade afeta intenção de compra e lealdade é uma intenção de compra. Na prática, Cronin e Taylor (1992, p. 67) mensuraram intenção de compra como "no próximo ano, meu uso de _ será (muito frequente/nada frequente)", ou seja, um indicador próximo da definição de lealdade. Por meio da investigação empírica, os autores encontram significância da hipótese em dois segmentos de quatro investigados. Em outro trabalho, Parasuraman, Berry e Zeithaml (1991, p. 433) associaram a qualidade, mensurada pela escala ServQual, "com a probabilidade de os consumidores recomendarem o serviço da firma para um amigo, indicando que todos os resultados são estatisticamente significativos". Nota-se que a probabilidade de recomendar o serviço é uma intenção de comportamento idêntica à intenção de recomprar um bem (isto é: lealdade). De tal modo, espera-se que qualidade e intenções comportamentais estejam ligadas positivamente (CRONIN, BRADY e HULT, 2000, VIEIRA, 2008). Assim:

$\mathrm{H}_{2 \mathrm{a}}$ : Existe uma relação linear positiva entre qualidade de eficiência e lealdade.

$\mathrm{H}_{2 \mathrm{~b}}$ : Existe uma relação linear positiva entre qualidade de sistema e lealdade.

$\mathrm{H}_{2 \mathrm{c}}$ : Existe uma relação linear positiva entre qualidade de privacidade e lealdade.

$\mathrm{H}_{2 \mathrm{~d}}$ : Existe uma relação linear positiva entre qualidade de preenchimento e lealdade.
Há suposições e comprovações de que as alterações no ambiente de loja têm impacto no comprometimento do cliente (VIEIRA, 2009). Prado e Santos (2006) hipotetizaram que qualidade e comprometimento estavam associados, devido ao fato de que qualidade tem um efeito indireto sobre comprometimento por meio da satisfação com o relacionamento. Esses pesquisadores não acharam resultados significativos. Contrariamente, Sharma e Patterson (1999) hipotetizaram que qualidade impactava comprometimento nos ambientes de serviços profissionais, encontrando resultados significativos. Por sua vez, Wetzels, Ruyter e Birgelen (1998) assumiram que qualidade técnica e qualidade funcional seriam preditoras de comprometimento, tanto afetivo como calculativo, descobrindo resultados mistos. Perante a inconsistência deparada, acredita-se que, como comprometimento é uma intenção comportamental, as percepções que o consumidor tem de qualidade do site afetam suas intenções no relacionamento (CRONIN e TAYLOR, 1992). Portanto:

$\mathrm{H}_{3 \mathrm{a}}$ : Existe uma relação linear positiva entre qualidade de eficiência e comprometimento.

$\mathrm{H}_{3 \mathrm{~b}}$ : Existe uma relação linear positiva entre qualidade de sistema e comprometimento.

$\mathrm{H}_{3 c}$ : Existe uma relação linear positiva entre qualidade de privacidade e comprometimento.

$\mathrm{H}_{3 \mathrm{~d}}$ : Existe uma relação linear positiva entre qualidade de preenchimento e comprometimento.

Diante da base teórica exposta, a Figura 1 resume as associações sugeridas pelo trabalho.

\section{MÉTODO DE PESQUISA}

Visando (a) verificar a escala de qualidade e (b) testar o modelo proposto, realizou-se uma pesquisa quantitativa de caráter conclusivo-descritiva, a qual se caracteriza como um levantamento de corte transversal único. A amostra foi composta pelos internautas que compraram qualquer produto ou serviço no ambiente de varejo eletrônico dentro do prazo mínimo de seis meses do momento da pesquisa (antes de agosto 2006). Estipulou-se esse prazo arbitrariamente para que esses indivíduos ainda se lembrassem da experiência do momento da compra. Como filtros adicionais não foram incluídos: consumidores que não compraram no varejo eletrônico, aqueles que compraram bens usados e internautas que não responderam o tipo de bem que compraram. A técnica de escolha da 
amostra foi por conveniência. A amostra do tipo bola de neve significa que cada respondente envia o questionário para a sua rede de contatos, os quais o encaminham para outros amigos, gerando assim uma bola de neve. Então, o processo visa o acréscimo no número de observações. A amostra inicial foi de 586 casos; todavia, após a purificação, foi reduzida para 515 casos.

\section{Definições dos construtos}

As definições conceituais utilizadas neste trabalho são: comprometimento é um desejo e uma intenção de continuar na relação, um desejo de fazer sacrifícios de curto prazo, uma confiança na estabilidade da relação, a importância da relação e a identificação da interiorização das normas e de valores do parceiro (KIM e FRAZIER, 1997). Confiança é entendida como a manifestação de confiança dos consumidores na confiabilidade e na integridade das trocas confidenciais de informação com o varejista eletrônico (MORGAN e HUNT, 1994). De acordo com Parasuraman, Zeithaml e Malhotra (2005, p. 217), qualidade é "a extensão pela qual um website facilita de modo efetivo e eficiente a compra e a entrega". Lealdade, para Oliver (1999, p. 34), é a "existência de um comprometimento profundo em comprar ou utilizar novamente um produto ou serviço consistentemente, no futuro, e assim provocar compras repetidas da mesma marca ou da mesma empresa, apesar de as influências situacionais e os esforços de marketing terem o potencial de causar um comportamento de mudança".

\section{Medidas}

Todos os instrumentos foram demarcados com cinco pontos de variação em escalas do tipo Likert, variando de "discordo totalmente" até "concordo totalmente". Para medir comprometimento, foi utilizada a escala de Vieira e Baptista (2007), sendo quatro itens para cada uma das três dimensões. Confiança foi verificada com dois itens do trabalho de Gummerus e outros (2004) e com outros dois itens da investigação de Anderson e Srinivasan (2003). A justificativa para a utilização de dois itens de Gummerus e outros (2004) foi que aquele autor só empregou dois indicadores para o construto, o que pode ser pouco. Assim, foram adicionados outros dois indicadores, além dos quatro propostos por Anderson e Srinivasan (2003). Foram excluídas duas variáveis por não representarem corretamente a confiança, sendo: "The performance of this website meets my expectations" " "This website can be counted on to successfully complete the transaction". A qualidade foi operacionalizada com base nas quatro dimensões da e-S-Qual de Parasuraman, Zeithaml e Malhotra (2005): eficiência (sete itens), disponibilidade do sistema (quatro itens), preenchimento (sete itens) e privacidade (três itens). Por fim, para verificar a lealdade, foi utilizada a escala do trabalho de Harris e Goode (2004), totalizando 16 indicadores para as quatro dimensões de lealdade cognitiva, afetiva, conativa e ação.

\section{ANÁLISE DE DADOS}

As análises iniciais foram realizadas com o objetivo de purificar e organizar a base de dados. Os principais pontos verificados foram valores extremos, aleatoriedade na omissão dos dados, curtose e assimetria, linearidade, normalidade e multicolinearidade. Após a exclusão dos dados com

Figura 1 - Modelo teórico proposto dos consequentes da qualidade

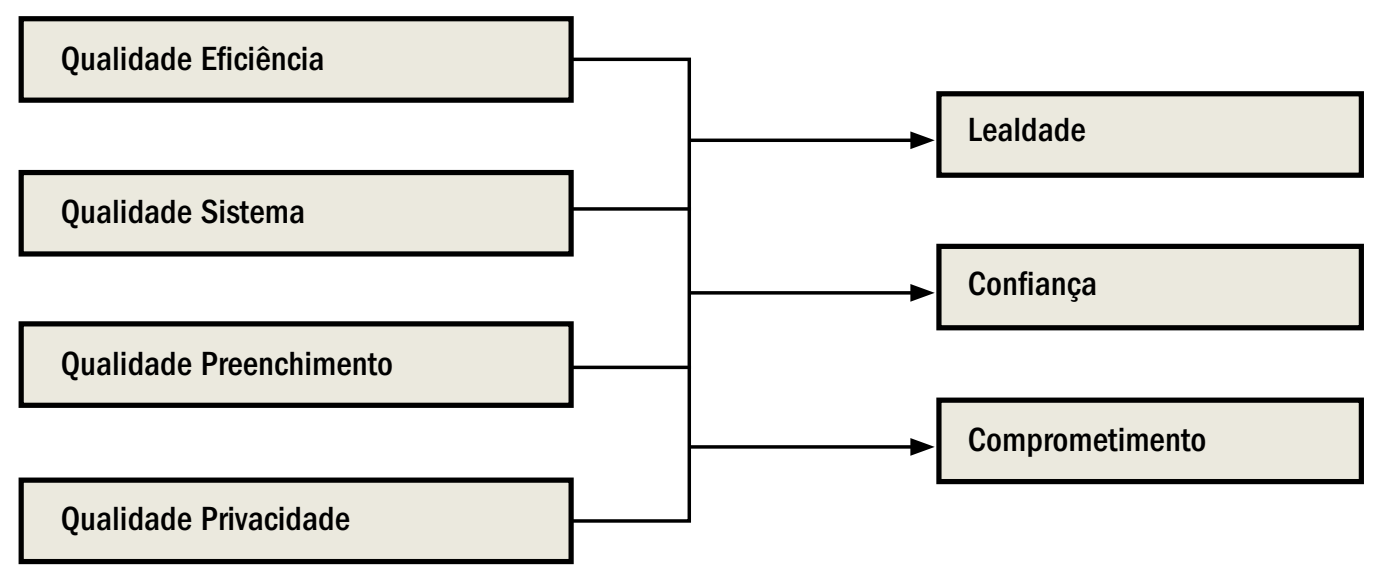


problemas, dos valores omissos e dos valores extremos, a amostra foi composta pelos consumidores que compraram em ambiente da internet. Desse total, 37,5\% compraram produtos como livros e revistas, comumente vendidos em sites como Livraria Cultura, Submarino, Amazon.com etc. Em seguida, 27\% dos consumidores compraram produtos eletrônicos em geral. Sessenta e seis indivíduos (13\%) responderam às questões lançadas por meio de uma compra de serviços de passagem aérea (Gráfico 2).

Como comparativo a esta pesquisa, o levantamento realizado pela empresa e-Bit identificou que os produtos mais comprados de modo geral são CDs, DVDs e vídeos, sendo que livros, jornais e revistas, que ficaram em primeiro nesta investigação, se posicionam em segundo naquele levantamento (média $=18 \%$ ). Maiores informações podem ser vistas no Gráfico 3.

Uma justificativa presumível para o posicionamento de livros, CDs e DVDs está no fato de que esses produtos têm maior peso para a criação do índice de e-inflação. A e-inflação, elaborada pelo Programa de Administração de Varejo da Fundação Instituto de Administração (ProvarFIA), apresenta em 2009 algumas mudanças em relação aos anos anteriores. Primeiro, o peso das categorias foi atualizado de acordo com a nova pesquisa do Provar e da e-Bit de Expectativa de Consumo na Internet. O Gráfico 4 apresenta os pesos das categorias dos produtos para cálculo da e-inflação em 2009. Quanto à e-inflação em si, livros (16\%), informática (11\%) e eletrônicos (9\%) tiveram os maiores pesos.

Após a análise inicial do banco de dados, foi feita uma análise descritiva da escala e-S-Qual, expondo suas respectivas médias e desvio padrão. A Tabela 2 apresenta as variáveis. Nota-se que as variáveis que tiveram maior média foram os itens do construto qualidade de preenchimento. Por exemplo, o item de maior concordância dos entrevistados foi "O site _ entrega a mercadoria quando prometido", que obteve uma média de $M_{\text {edia }}=4,43$. Isso indica a preocupação do comprador em receber a mercadoria dentro do prazo estipulado pela organização. $\mathrm{O}$ indicador com menor média de concordância $\left(M_{\text {edia }}=\right.$ $3,57)$ e com maior desvio padrão $(d . p .=1,11)$ foi o "O site _ não divulga minha informação pessoal para outros sites", referindo-se às informações sigilosas dos clientes. De modo geral, muitos dos itens de qualidade de preenchimento foram bem avaliados.

\section{Análise fatorial da e-S-Qual}

$\mathrm{Na}$ sequência, verificou-se isoladamente a dimensionalidade de cada construto do modelo por meio da análise fatorial exploratória. O procedimento de extração foi o varimax em conjunto com a análise dos componentes principais. Para reter os fatores, os critérios empregados foram: cargas fatoriais dos indicadores maiores que 0,30 e autovalores maiores do que um.

Gráfico 2 - Produtos comprados, segundo a pesquisa (2006)

Livro/revista
Passagem aérea - Serviço Bancário
Outros

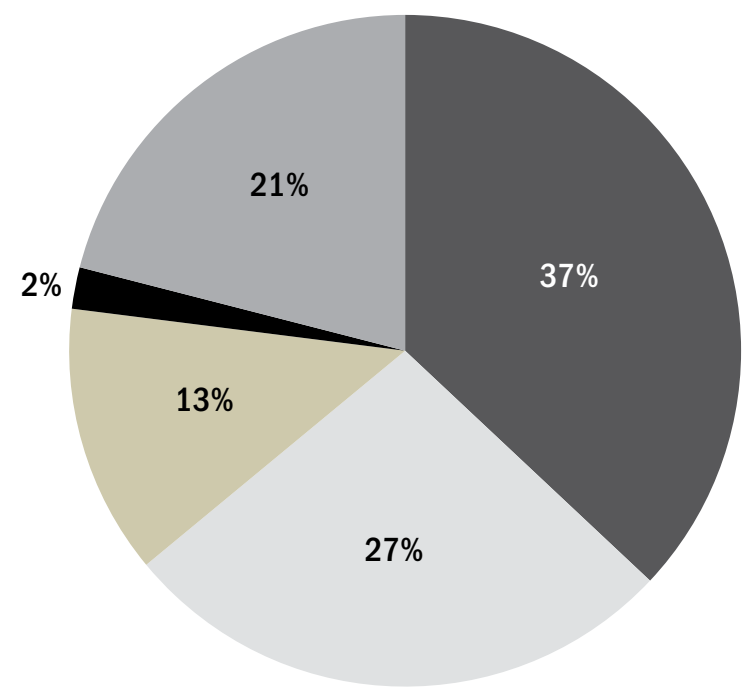


Gráfico 3 - Produtos mais vendidos no Brasil no varejo eletrônico em \%
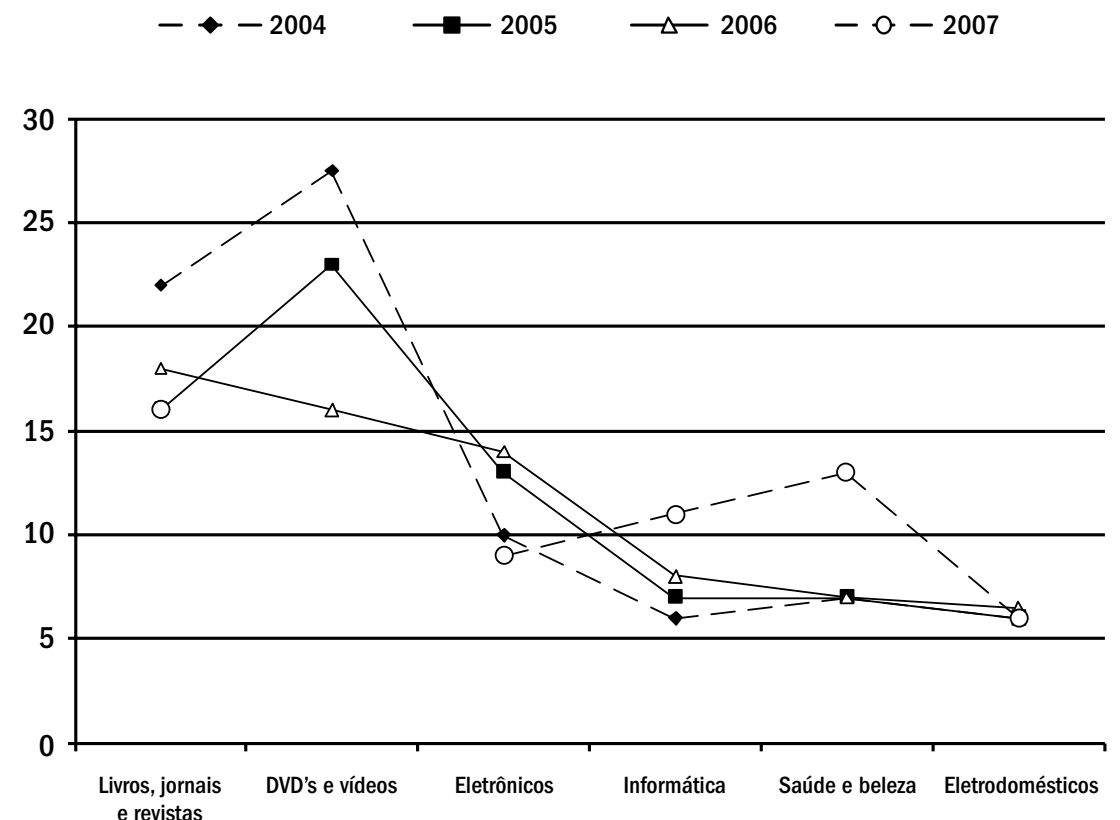

Fonte: Levantamento realizado pela empresa e-Bit www.ebitempresa.com.br; Compilação: www.e-commerce.org.br eixo Y em porcentagem de vendas

Gráfico 4 - E-flation (índice de inflação na internet), peso das categorias 2008 para janeiro 2009

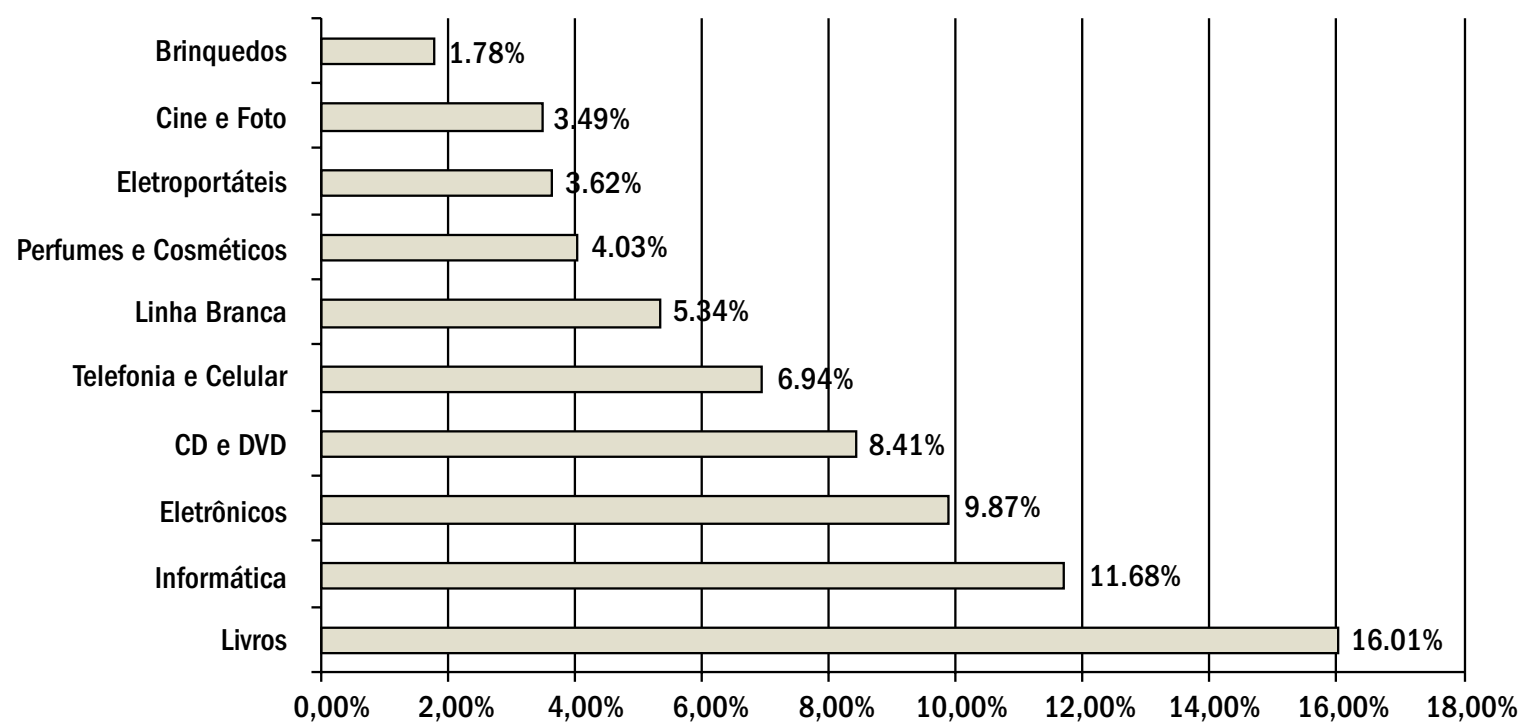

Nota: Para a apuração da variação de preços, são consideradas as lojas virtuais preferidas pelos internautas, conforme apurado na pesquisa de Intenção de Compra na Internet, realizada em parceria pelo Provar, pela Felisoni \& Associados e pela e-BIt empresa. A cesta de produtos por categoria é composta a partir das listas contendo os "campeões de vendas" nos sites pesquisados. Fonte: http://www. provar.org/pesquisa_sef-2009-I.asp 


\section{VALTER AFONSO VIEIRA}

De acordo com Zwick e Velicer (1986), o sistema de extração com autovalor maior do que um erra em $78 \%$ dos casos, no que tange à estimação do número de componentes, uma vez que ocorre a superextração dos componentes. O estudo dos autores comparou cinco opções de extração, sendo eles o teste de Bartlett, a média parcial mínima, o teste scree, o autovalor maior do que um e a análise paralela. O resultado da simulação de Monte Carlo sugeriu que o sistema da análise paralela erra na estimação do número de fatores em apenas $8 \%$ dos casos. A análise paralela visa comparar os autovalores reais obtidos pela base de dados com autovalores randômicos artificiais gerados pela syntax. O número ideal de componentes a ser retido deveria ser quando o autovalor real é maior do que o autovalor artificial, nessa ordem. Assim, para reter os fatores neste trabalho, ambos os métodos foram utilizados.
Comparando o autovalor real $v$ s. o artificial, o resultado correto doe número de fatores retidos para qualidade foi $(8,10 ; 2,03 ; 1,61$ e 1,44 vs. 1,$38 ; 1,32 ; 1,27$ e 1,23$)$, para comprometimento foi $(4,66 ; 1,52$ e 1,22 vs. 1,$24 ; 1,17$ e 1,12$)$ e para confiança foi $(3,14$ vs. 1,09$)$. A estrutura de lealdade não foi confirmada utilizando ambos os procedimentos, autovalor maior do que um e análise paralela $(4,21 ; 1,49 ; 0,92$ e 0,65 vs. 1,$30 ; 1,23 ; 1,18$ e 1,14$)$. Contudo, a dimensionalidade da lealdade foi confirmada quando fixados os fatores em quatro.

No tocante à dimensionalidade de qualidade, esperavase uma estrutura com quatro fatores. Os resultados indicaram um carregamento perfeito da escala de e-S-Qual, sendo o primeiro fator qualidade de eficiência, a qual explica a maior variância do fenômeno (36\%). Qualidade de preenchimento foi a segunda dimensão que mais explica a variância do construto $(9,23 \%)$. Em terceiro, qualidade do

Tabela 2 - Análise descritiva das variáveis da e-S-Qual

\begin{tabular}{|c|c|c|}
\hline VARIÁVEIS & MÉDIA & DESV. PAD \\
\hline No site __ é fácil encontrar o quê necessito. & 4,2272 & 0,75 \\
\hline 0 site ___ facilita a navegação por onde eu quero & 4,0817 & 0,78 \\
\hline 0 site __ facilita completar a transação rapidamente & 3,9863 & 0,92 \\
\hline A informação no site ___ é bem organizada & 3,9881 & 0,82 \\
\hline As páginas no site ___ carregam rapidamente & 3,7583 & 0,93 \\
\hline 0 site ___ é fácil de usar & 4,1090 & 0,80 \\
\hline 0 site ___ auxilia o usuário a navegar dentro dele de modo rápido & 3,8604 & 0,85 \\
\hline 0 site __ é bem organizado & 4,0174 & 0,79 \\
\hline 0 site ___ está sempre disponível para fazer negócios & 4,2494 & 0,89 \\
\hline 0 site funciona perfeitamente & 4,0564 & 0,85 \\
\hline 0 site __ não sai do ar & 4,1586 & 0,98 \\
\hline 0 site __ não trava depois de eu ter feito meu pedido & 4,2040 & 0,91 \\
\hline 0 site ___ entrega a mercadoria quando prometido & 4,4265 & 0,78 \\
\hline 0 site ___ entrega a mercadoria dentro de um tempo justo & 4,3629 & 0,81 \\
\hline 0 site ___ entrega a mercadoria de modo muito rápido & 3,9157 & 1,02 \\
\hline 0 site __ entrega a mercadoria quando solicitada & 4,3248 & 0,84 \\
\hline 0 site __ parece ter em estoque os itens que são apresentados no site & 4,0309 & 1,02 \\
\hline 0 site __ é confiável com relação as suas ofertas & 4,3609 & 0,78 \\
\hline 0 site __ faz promessas sobre a entrega dos produtos & 3,8234 & 1,18 \\
\hline 0 site __ protege a informação sobre meu comportamento de compra & 3,7679 & 1,06 \\
\hline 0 site __ não divulga minha informação pessoal para outros sites & 3,5734 & 1,12 \\
\hline 0 site __ protege a informação sobre meu cartão de crédito & 4,0823 & 0,95 \\
\hline
\end{tabular}


sistema teve uma variância de 7,33\%. Por fim, qualidade de privacidade obteve as cargas fatoriais mais altas da escala, ficando agrupada de modo coerente com o previsto. Assim, os resultados corroboram a estrutura multidimensional de Parasuraman, Zeithaml e Malhotra (2005). Em termos do desempenho da análise fatorial exploratória, os ajustamentos foram todos acima do recomendado pela literatura (Kaiser Meyer Olkin $=0,92$; Bartlett's $\chi^{2}=5436,737$; d.f. $=231$ e $p<0,001)$. Todavia, a variável - "O site _ faz promessas sobre a entrega dos produtos" obteve baixa car- ga fatorial na sua respectiva dimensão $(\lambda=0,24)$ e para o teste do modelo ela foi eliminada (Tabela 3 ).

Com base nesses achados, infere-se que a sugestão de Parasuraman, Zeithaml e Malhotra (2005) obteve bom carregamento de indicadores nos locais onde eram pressupostos, bons valores de ajustamento dos dados e alta confiabilidade da escala. A Tabela 4 apresenta os resultados confirmatórios dos modelos rivais de qualidade. O primeiro modelo foi o que melhor se ajustou aos dados.

Tabela 3 - Análise fatorial exploratória do construto qualidade

\begin{tabular}{|c|c|c|c|c|c|c|c|c|}
\hline \multirow[t]{2}{*}{ VARIÁVEIS } & \multicolumn{4}{|c|}{ PCA-VARIMAX } & \multicolumn{4}{|c|}{ PAF-QUARTIMAX } \\
\hline & EFI & PRE & SIST & PRIV & EFI & PRE & SIST & PRIV \\
\hline 0 site ___ é bem organizado & 0,78 & 0,20 & 0,18 & 0,15 & 0,84 & $-0,01$ & $-0,03$ & 0,02 \\
\hline A informação no site ___ é bem organizada & 0,77 & 0,24 & 0,15 & 0,15 & 0,81 & 0,04 & $-0,07$ & 0,02 \\
\hline 0 site ___ facilita a navegação por onde eu quero & 0,76 & 0,20 & 0,13 & 0,05 & 0,79 & 0,02 & $-0,05$ & $-0,07$ \\
\hline 0 site __ auxilia o usuário a navegar dentro dele de modo rápido & 0,73 & 0,13 & 0,12 & 0,13 & 0,75 & $-0,05$ & $-0,04$ & 0,03 \\
\hline 0 site ___ é fácil de usar & 0,73 & 0,19 & 0,27 & 0,11 & 0,73 & $-0,01$ & 0,10 & $-0,01$ \\
\hline No site ___ é fácil encontrar o quê necessito. & 0,70 & 0,12 & 0,19 & 0,03 & 0,70 & $-0,05$ & 0,03 & $-0,06$ \\
\hline 0 site ___ facilita completar a transação rapidamente & 0,64 & 0,26 & 0,12 & 0,19 & 0,61 & 0,10 & $-0,03$ & 0,07 \\
\hline As páginas no site ___ carregam rapidamente & 0,61 & 0,13 & 0,28 & 0,09 & 0,56 & $-0,03$ & 0,14 & $-0,01$ \\
\hline 0 site ___ entrega a mercadoria quando prometido & 0,17 & 0,82 & 0,11 & 0,01 & $-0,04$ & 0,90 & $-0,02$ & $-0,12$ \\
\hline 0 site ___ entrega a mercadoria dentro de um tempo justo & 0,19 & 0,77 & 0,09 & 0,15 & 0,00 & 0,77 & $-0,05$ & 0,03 \\
\hline 0 site __ entrega a mercadoria de modo muito rápido & 0,20 & 0,77 & 0,12 & 0,18 & 0,00 & 0,77 & $-0,02$ & 0,07 \\
\hline 0 site ___ entrega a mercadoria quando solicitada & 0,09 & 0,75 & 0,12 & 0,08 & $-0,08$ & 0,73 & 0,02 & $-0,01$ \\
\hline $\begin{array}{l}0 \text { site } \_ \text {parece ter em estoque os itens que são apresenta- } \\
\text { dos no site }\end{array}$ & 0,19 & 0,61 & 0,08 & 0,07 & 0,09 & 0,50 & $-0,01$ & 0,01 \\
\hline 0 site __ é confiável com relação as suas ofertas & 0,28 & 0,56 & 0,27 & 0,18 & 0,13 & 0,44 & 0,14 & 0,07 \\
\hline 0 site __ faz promessas sobre a entrega dos produtos & 0,10 & 0,24 & 0,15 & 0,04 & 0,06 & 0,16 & 0,07 & 0,02 \\
\hline 0 site __ não sai do ar & 0,16 & 0,14 & 0,83 & 0,11 & $-0,13$ & $-0,04$ & 0,93 & 0,00 \\
\hline 0 site __ não trava depois de eu ter feito meu pedido & 0,24 & 0,17 & 0,75 & 0,10 & 0,04 & 0,01 & 0,71 & 0,00 \\
\hline 0 site funciona perfeitamente & 0,38 & 0,23 & 0,69 & 0,16 & 0,18 & 0,04 & 0,63 & 0,04 \\
\hline 0 site ___ está sempre disponível & 0,23 & 0,16 & 0,66 & 0,03 & 0,11 & 0,03 & 0,52 & $-0,04$ \\
\hline 0 site __ não divulga minha informação pessoal para outros sites & 0,12 & 0,13 & 0,07 & 0,86 & 0,04 & $-0,03$ & $-0,06$ & 0,85 \\
\hline $\begin{array}{l}0 \text { site ___ protege a informação sobre meu comportamento de } \\
\text { compra }\end{array}$ & 0,20 & 0,14 & 0,05 & 0,84 & $-0,06$ & $-0,02$ & $-0,01$ & 0,85 \\
\hline 0 site __ protege a informação sobre meu cartão de crédito & 0,15 & 0,17 & 0,19 & 0,71 & 0,01 & 0,05 & 0,10 & 0,55 \\
\hline
\end{tabular}

Nota: Variância explicada = 36,82\%; 9,23\%, 7,33\% e 6,56\% (rotação varimax, componentes principais, lado esquerdo da tabela). Total = $59,96 \%$; autovalores = 8,10; 2,03; 1,61 e 1,44. Uma nova rotação com 50\% da amostra de modo aleatório demonstrou um carregamento perfeito da solução. Lado direito da tabela (rotação principal axis factoring, quartimax). Dimensões EFI = Eficiência, PRIV = Privacidade; $\mathrm{SIS}=$ Sistema; PRE $=$ Preenchimento. 
Dando sequência, buscou-se verificar se os construtos diferem realmente dos outros sugeridos pelo modelo por meio da análise discriminante (ver FORNELL e LARCKER, 1981 e MATOS e outros, 2009). O procedimento é comparar a média da variância extraída dos construtos (AVE) de qualidade com a correlação ao quadrado de confiança, de comprometimento e de lealdade.

A matriz de correlação dos construtos é exposta na Tabela 5 com a confiabilidade na diagonal principal. Como interpretação geral, a maioria das correlações é significativa a $p<0,05$. A maior correlação encontrada foi entre os construtos lealdade conativa e lealdade cognitiva $(r=0,76$; $p<0,001)$, sugerindo uma variância compartilhada de $58 \%$.

Quanto ao construto qualidade do site, o valor médio de correlação com confiança foi de $r=0,50(p<0,01)$. Qualidade de sistema tem alta associação com qualidade de eficiência, o que indica que o primeiro é antecedente do segundo ( $r=0,66 ; p<0,01)$. Os quatro construtos de qualidade não tiveram valores altos com a lealdade $\left(r_{\text {médio }}\right.$ $=0,32 ; p<0,01$ ).

Por fim, para teste do modelo sugerido, a modelagem de equações estruturais foi utilizada. Os seguintes achados decretaram o desempenho do modelo estrutural: $\chi^{2} /$ d.f. $=$ 2,98; $p<0,000 ; \mathrm{GFI}=0,80 ; \mathrm{AGFI}=0,77 ; \mathrm{CFI}=0,85 \mathrm{e}$ RMSEA $=0,059$. Percebe-se que os índices de ajustamento geral do modelo estrutural e os índices comparativos são moderados, pois estão abaixo do indicado pela literatura. Uma justificativa para esse agravante pode estar no excesso de parâmetros do modelo e na quantidade de hipóteses estabelecidas. A Tabela 6 demonstra o exame das hipóteses.

Inicialmente, observa-se que a qualidade do site varejista, independentemente da dimensão, é relevante para aumentar a confiança e a intenção de retorno do cliente

Tabela 4 - Ajustamentos dos modelos concorrentes

\begin{tabular}{|l|c|c|c|c|c|c|c|}
\hline \multicolumn{1}{|c|}{ MODELOS TESTADOS } & X'/D.F. & P-VALOR & GFI & NFI & TLI & CFI & RMSEA \\
\hline 1. Qualidade de segunda ordem & 2,99 & $p<0,000$ & 0,91 & 0,90 & 0,92 & 0,93 & 0,06 \\
\hline 2. Qualidade um único fator geral & 10,06 & $p<0,000$ & 0,69 & 0,65 & 0,64 & 0,67 & 0,13 \\
\hline 3. Qualidade com correlação livre & 3,01 & $p<0,000$ & 0,91 & 0,90 & 0,92 & 0,93 & 0,06 \\
\hline 4. Qualidade sem correlação livre & 5,39 & $p<0,000$ & 0,83 & 0,81 & 0,82 & 0,84 & 0,09 \\
\hline
\end{tabular}

Nota: 0 teste de qui-quadrado $\left(\Delta \chi^{2}\right)$ não apresentou significância entre os modelos 1 e 3; $p<0,19$. Não foi manipulado a correlação entre erros de variáveis e distúrbios objetivando aumentar os ajustamentos

\section{Tabela 5 - Matriz de correlação}

\begin{tabular}{|c|c|c|c|c|c|c|c|c|c|c|c|c|c|c|}
\hline VARIÁVEIS & 1 & 2 & 3 & 4 & 5 & 6 & 7 & 8 & 9 & 10 & 11 & 12 & AVE & $\mathrm{CC}$ \\
\hline 1. Qualidade Eficiência & 0,90 & & & & & & & & & & & & 0,53 & 0,90 \\
\hline 2. Qualidade Sistema & 0,66 & 0,82 & & & & & & & & & & & 0,54 & 0,82 \\
\hline 3. Qualidade Preenchimento & 0,56 & 0,52 & 0,85 & & & & & & & & & & 0,50 & 0,86 \\
\hline 4. Qualidade Privacidade & 0,43 & 0,38 & 0,41 & 0,79 & & & & & & & & & 0,57 & 0,80 \\
\hline 5. Confiança & 0,58 & 0,55 & 0,52 & 0,52 & 0,91 & & & & & & & & 0,72 & 0,91 \\
\hline 6. Comprometimento Afetivo & 0,31 & 0,20 & 0,26 & 0,63 & 0,28 & 0,84 & & & & & & & 0,60 & 0,85 \\
\hline 7. Comprometimento Calcul. & 0,15 & 0,01 & 0,11 & 0,10 & 0,09 & 0,51 & 0,76 & & & & & & 0,49 & 0,79 \\
\hline 8. Comprometimento Resist. & 0,28 & 0,22 & 0,21 & 0,32 & 0,22 & 0,55 & 0,50 & 0,80 & & & & & 0,60 & 0,80 \\
\hline 9. Lealdade Afetiva & 0,37 & 0,36 & 0,37 & 0,26 & 0,58 & 0,14 & 0,03 & 0,05 & 0,71 & & & & 0,56 & 0,72 \\
\hline 10. Lealdade Conativa & 0,39 & 0,35 & 0,29 & 0,33 & 0,40 & 0,52 & 0,41 & 0,47 & 0,18 & 0,87 & & & 0,77 & 0,87 \\
\hline 11. Lealdade Cognitiva & 0,46 & 0,43 & 0,38 & 0,46 & 0,47 & 0,47 & 0,34 & 0,41 & 0,36 & 0,76 & 0,76 & & 0,57 & 0,79 \\
\hline 12. Lealdade Ação & 0,40 & 0,37 & 0,37 & 0,42 & 0,38 & 0,62 & 0,45 & 0,59 & 0,21 & 0,69 & 0,72 & 0,83 & 0,62 & 0,83 \\
\hline
\end{tabular}

Nota: Sublinhadas as não significativas; todas as demais correlações acima de 0,20 são significativas a $p<0,01 ;$ dentre 0,10 e $0,19, p$ $<0,05 ; \mathrm{AVE}=$ média da variância extraída; $\mathrm{CC}=$ confiabilidade composta; alpha de Cronbach na diagonal principal. 
(todos $p<0,05)$. Isso porque todas as dimensões de qualidade impactaram tanto a confiança quanto a lealdade. Em outras palavras, caso o gestor necessite elevar a confiança do consumidor para uma compra e essa compra vire algo rotineiro (lealdade), os fatores da qualidade de facilidade, de velocidade, de funcionalidade, de promessa, de segurança e de sigilo nas informações são fundamentais para o processo.

No que tange à lealdade, destaque para qualidade privacidade $(\beta=0,36 ; p<0,001)$ e qualidade de eficiência ( $\beta=0,30 ; p<0,001)$, pois ambas obtiveram os maiores valores de impacto (betas). Vale lembrar que qualidade de eficiência é definida como a facilidade e velocidade de acessar o site, e que qualidade de privacidade representa o grau no qual o site demonstra segurança e sigilo nas informações particulares do consumidor.

Com relação à variável dependente confiança, qualidade privacidade $(\beta=0,33 ; p<0,001)$ e qualidade de eficiência $(\beta=0,31 ; p<0,001)$ também tiveram os maiores impactos como preditoras. Observa-se um peso um pouco mais baixo, mas significativo, de duas outras relações: qualidade preenchimento $(\beta=0,22 ; p<0,001)$ - sendo a extensão na qual o site promete entregar o pedido de modo correto e eficaz - e qualidade do sistema $(\beta=0,25$; $p<0,001)$ - o qual representa o grau no qual o site demonstra segurança e sigilo nas informações particulares do consumidor.

A qualidade não foi uma preditora de comprometi- mento. Das quatro associações hipotetizadas, apenas duas foram significativas (25\%). Qualidade de privacidade $(\beta=0,34 ; p<0,001)$ e qualidade de eficiência $(\beta=0,26$; $p<0,001)$ impactaram positivamente o comprometimento; as demais não. Uma justificativa para o resultado não significativo é que como comprometimento, neste trabalho, é um desejo e uma intenção de continuar na relação, uma confiança na estabilidade da relação, a importância da relação e a identificação da interiorização das normas e de valores do parceiro (KIM e FRAZIER, 1997), os consumidores podem não achar suficiente a qualidade do sistema e de preenchimento como fatores significativos para continuar na relação com o varejista fazendo sacrifícios de curto prazo.

Algumas questões foram apresentadas no início deste trabalho. (1) Existe efeito diferente de cada componente de qualidade sobre confiança e intenção de retorno do cliente? Sim, as dimensões de qualidade preenchimento e de sistema tiveram efeitos não significativos no comprometimento; todavia, na lealdade e na confiança o efeito foi significativo e constante. (2) Quais aspectos da qualidade são mais relevantes no contexto de compra virtual? Os fatores qualidade de eficiência e de privacidade, de modo geral, foram as mais regulares, estáveis e importantes em explicar as intenções comportamentais. (3) O instrumento e-S-Qual possui confiabilidade e é multidimensional? Conforme predito pela teoria, a escala é multidimensional e todos os quatro fatores possuem alta confiabilidade.

Tabela 6 - Resultado das hipóteses

\begin{tabular}{|l|l|l|l|l|l|}
\hline \multicolumn{1}{|c|}{ RELAÇÕES HIPOTEIIZADAS PELO MODELO } & $\beta$ & ERRO & CR. & P-VALOR \\
\hline Qualidade Eficiência & $\rightarrow$ Lealdade & 0,301 & 0,057 & 4,718 & 0,000 \\
\hline Qualidade Sistema & $\rightarrow$ Lealdade & 0,160 & 0,057 & 2,598 & 0,009 \\
\hline Qualidade Preenchimento & $\rightarrow$ Lealdade & 0,125 & 0,061 & 2,131 & 0,033 \\
\hline Qualidade Privacidade & $\rightarrow$ Lealdade & 0,362 & 0,039 & 6,143 & 0,000 \\
\hline Qualidade Privacidade & $\rightarrow$ Comprometimento & 0,343 & 0,047 & 5,053 & 0,000 \\
\hline Qualidade Preenchimento & $\rightarrow$ Comprometimento & 0,085 & 0,070 & 1,319 & 0,187 \\
\hline Qualidade Sistema & $\rightarrow$ Comprometimento & $-0,066$ & 0,066 & $-0,976$ & 0,329 \\
\hline Qualidade Eficiência & $\rightarrow$ Comprometimento & 0,264 & 0,066 & 3,707 & 0,000 \\
\hline Qualidade Privacidade & $\rightarrow$ Confiança & 0,327 & 0,033 & 6,216 & 0,000 \\
\hline Qualidade Preenchimento & $\rightarrow$ Confiança & 0,225 & 0,052 & 4,206 & 0,000 \\
\hline Qualidade Sistema & $\rightarrow$ Confiança & 0,255 & 0,049 & 4,581 & 0,000 \\
\hline Qualidade Eficiência & $\rightarrow$ Confiança & 0,313 & 0,048 & 5,525 & 0,000 \\
\hline
\end{tabular}

Nota: C.R. critical ratio (t-valor); beta padronizado; estimativa por Maximum Likelihood; R2 confiança = 0,49;

$\mathrm{R} 2$ lealdade $=0,39 ; \mathrm{R} 2$ comprometimento $=0,24$. 


\section{CONSIDERAÇÕES FINAIS}

\section{Contribuições gerenciais}

Como aplicação prática, percebe-se a relevância da dimensão qualidade de privacidade dentre as dimensões da qualidade do site. Esse resultado indica aos profissionais de Marketing que, para o consumidor avaliar positivamente um varejista eletrônico e ter maiores chances de retorno, é essencial que o site tenha privacidade e segurança das informações particulares dos usuários. A questão da qualidade de privacidade é, por exemplo, o sigilo do RG, do $\mathrm{CPF}$ do número do cartão de crédito, da não venda de cadastro pessoal para outras empresas etc. Valle (2009) suporta essa informação e comenta que o número de programas criados para facilitar o roubo de senhas cresceu 400\% só em 2008.

Segundo, salienta-se gerencialmente que o ato de "cumprir o que se promete" (isto é, qualidade de preenchimento) também ficou fortemente evidenciado na pesquisa. Assim, esse conceito pode ser traduzido em termos de data de entrega (prazo), sistema de pagamento (boleto, transferência eletrônica, cartão de crédito) ou atendimento por e-mail. Logo, é essencial o investimento nesses quesitos por parte das organizações.

Terceiro, para o gestor empresarial, a dimensão da qualidade de preenchimento não se mostrou um forte explicador do comprometimento. Uma possível explicação é que o preenchimento pode ser visto pelo cliente que compra on-line como uma obrigação de a empresa eletrônica oferecer e não como um fator de diferenciação para iniciar um programa de comprometimento de longo prazo (ex. bônus, milhagem, cartão fidelidade). Talvez em outra situação, com clientes que já tenham um relacionamento antigo com a empresa, essa dimensão de preenchimento possua maior relevância. De todo modo, tal proposição de moderação do tempo de relacionamento do usuário com o varejista deve ser validada por investigações empíricas.

Quarto, o profissional de Marketing pode ver os resultados desta pesquisa como um fluxograma indicando que: a lealdade e a confiança do consumidor com o site dependem significativamente de quatro fatores de qualidade eficiência, sistema, preenchimento e privacidade, sendo esse último o mais importante dos quatro. Essa discussão é relevante, pois Hackman e outros (2006) já comprovaram empiricamente o impacto significativo da qualidade eletrônica sobre valor e satisfação. Esta pesquisa extende tal achado para lealdade e confiança. Assim, a qualidade do site tem ligação com satisfação, valor, lealdade, confiança e parcialmente com comprometimento.
Por fim, para instituições reguladoras ou institutos que verificam a internet brasileira, Índices de Avaliação de Qualidade Eletrônica (IAQE) podem ser sugeridos para a aferição periódica dos sites no Brasil. Por exemplo, a Agência Nacional de Energia Elétrica possui o Índice Aneel de Satisfação do Consumidor (IASC), instituído em 2000, e a Agência Nacional de Telecomunicações possui o Índice Satisfação do Consumidor (ISC). Logo, devido à existência e validação de uma escala para mensuração da qualidade, instituições empresariais podem utilizar o instrumento para a criação de um indicador de qualidade do varejo eletrônico nacional - dividido e medido até mesmo por segmento varejista (ex. banco, saúde, entretenimento), por periodicidade (trimestral, semestral) e por faixas (ex. navega mais/menos do que 10 horas por semana; percebe menor/maior índice de qualidade).

Quinto, todos os anos, a e-Bit entrega o troféu Prêmio Excelência em Qualidade Comércio Eletrônico B2C para as melhores lojas do e-commerce brasileiro, que alcançaram a medalha Diamante, avaliadas por seus próprios consumidores. No ano de 2009, a e-Bit inovou e também premiou as três melhores lojas nas categorias Diamante Azul, Ouro, Prata e Bronze escolhidas por votação popular durante os meses de junho, julho e agosto de 2009. As organizações podem utilizar a estrutura da escala aqui verificada para segmentar quais varejistas possuem maior segurança, maior eficiência, dentre outras condições na perspectiva do consumidor. Isso pode auxiliar a promover ainda mais a avaliação de sites e a geração de relacionamentos empresa-cliente mais efetivos. As empresas ganhadoras do prêmio estão apresentadas na Figura 2.

\section{Contribuições teóricas}

O construto qualidade de serviços tem sido amplamente pesquisado na literatura de Marketing em termos de antecedentes, consequentes, dimensões, mensurações etc. (ZEITHAML, BERRY e PARASURAMAN, 1996). No entanto, há uma carência na realização não somente de pesquisas sobre a qualidade de serviços em varejo eletrônico, como também sobre a definição e a dimensionalidade do construto nesse ambiente. Sob essa lacuna, o trabalho buscou compreender a validade da escala de qualidade no varejo eletrônico, suportando a estrutura.

Primeiro, conclui-se que a escala de qualidade se mostrou multidimensional e com quatro dimensões. Efetivamente, dos quatro fatores que deveriam existir, todos foram confirmados pelo trabalho - eficiência, sistema, preenchimento e privacidade -, sendo que a dimensão qualidade de eficiência foi o maior reflexo do fenômeno qualidade eletrônica (36\%). Esse achado é coerente com 
o trabalho original de Parasuraman, Zeithaml e Malhotra (2005), mas contrário ao de Boshoff (2007), o qual, verificando a escala, identificou seis fatores. Segundo, todos os resultados de confiabilidade do instrumento se mostraram eficientes. Mesmo utilizando indicadores de confiabilidade diferentes, tais como a confiabilidade composta ou a variância média extraída, todas as confiabilidades das dimensões ficaram acima dos limites indicados. Isso atesta ainda mais a segurança de utilizar tal instrumento e/ou uma subdimensão de modo isolado. Terceiro, uma contribuição teórica advém do suporte aos argumentos encontrados na literatura do impacto da qualidade sobre as intenções comportamentais. Isso solidifica ainda mais resultados do ambiente convencional e abre caminho para a inserção de outros construtos em modelos de qualidade, tais como custos de mudança, imagem, e desempenho.

\section{Pesquisas futuras}

Quanto às pesquisas futuras, sugerem-se investigações que analisem se a qualidade de serviços do site tem impacto negativo nos custos de mudança. Ou seja, uma melhor

Figura 2 - Troféu Prêmio Excelência em Qualidade Comércio Eletrônico B2C e-Bit (2009)

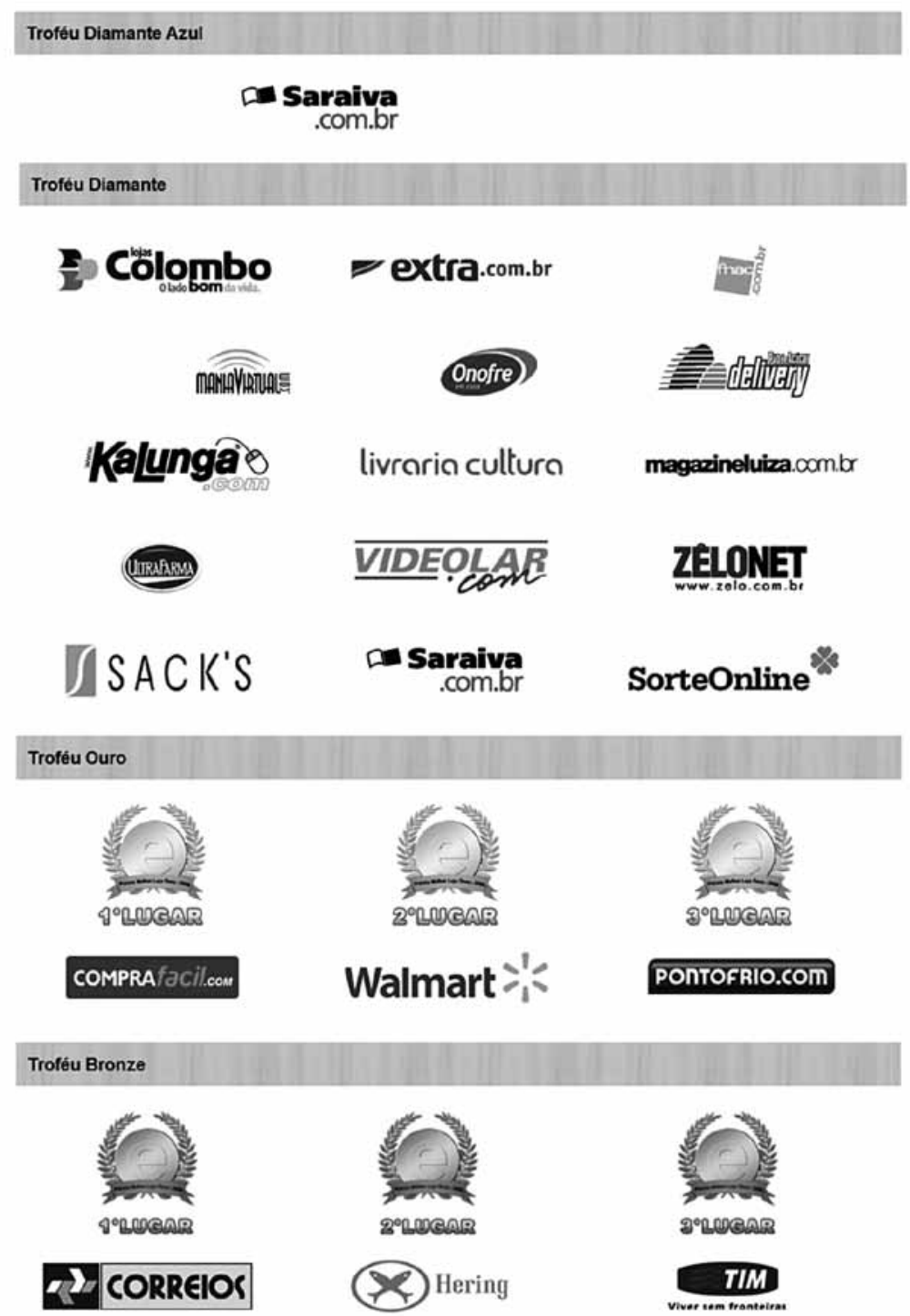

Fonte: http://www.ebit.com.br/premios/premiacao2009.asp 
percepção de qualidade do site tende a diminuir a tendência de mudar de varejista para a realização de compras. Segundo, pesquisas podem comparar o desempenho da escala e-S-Qual com outras medidas sugeridas pela literatura, tais como WebQual, SiteQual, PirQual e e-TailQ. Até que ponto essas medidas são associadas, uma vez que mensuram o mesmo conceito? Qual medida gera maior percepção de qualidade do site? Terceiro, pesquisas futuras podem verificar a associação da qualidade do site com outras intenções comportamentais, tais como: a imagem da empresa varejista, o boca a boca dos internautas, desempenho financeiro e rapidez de compra (mensurados via IP do computador). Quarto, pesquisas podem verificar até que ponto a escala de recuperação de serviços no varejo eletrônico, e-recS-Qual, influencia as intenções comportamentais dos consumidores. A e-recS-Qual foi outra medida proposta pelo trabalho de Parasuraman, Zeithaml e Malhotra (2005).

\section{NOTA DE AGRADECIMENTO}

O autor agradece os comentários de Carlos Alberto Vargas Rossi, Claudio Damacena, Cristiane P. Santos e Luiz A. Slongo e também reconhece os precisos apontamentos dos revisores. Trabalho baseado na Dissertação de Mestrado.

\section{REFERÊNCIAS}

ANDERSON, R. E; SRINIVASAN, S. S. E-satisfaction and e-loyalty: a contingency framework. Psychology and Marketing, v. 20, n. 2, p. 123-138, 2003.

BOSHOFF, C. A psychometric assessment of e-S-Qual: a scale to measure electronic service quality. Journal of Electronic Commerce Research, v. 8, n. 1, p. 101-114, 2007.

BOULDING, W; STAELIN, R; KALRA, A; ZEITHAML, V. A dynamic process model of service quality: from expectations to behavioral intentions. Journal of Marketing Research, v. 30, n. 1, p. 7-27, 1993.

COLLIER, J. E; BIENSTOCK, C. C. Measuring service quality in e-retailing. Journal of Services Research, v. 8, n. 3, p. 206-272, 2006.

CRONIN J. J; TAYLOR, S. A. Measuring service quality: a reexamination and extension. Journal of Marketing, v. 56, n. 3, p. 55-68, 1992.

CRONIN, J. J; TAYLOR, S. A. ServPerf versus ServQual: reconciling performance-based and perceptions-minus-expectations measurement of service quality. Journal of Marketing, v. 58, n. 1, p. 125-131, 1994.
CRONIN, J. J; BRADY, M. K; HULT, G. T. M. Assessing the effects of quality, value, and customer satisfaction on consumer behavioral intentions in service environments. Journal of Retailing, v. 76, n. 1, p. 193-209, 2000.

FORNELL, C; LARCKER, D. F. Evaluating structural equations models with unobservable variables and measurement error. Journal of Marketing, v. 18, n. 1, p.3 9-50, 1981

GEFEN, D. Customer Loyalty in e-commerce. Journal of the Association for Information Systems, v. 3, n. 1, p. 27-51, 2002.

GREWAL, D; MONROE, K. B; KRISHNAN, R. The effects of price comparison advertising on buyers' perceptions of acquisition value and transaction value. Journal of Marketing, v. 62, n. 2, p. 46-59, 1998.

GUMMERUS, J; LILJANDER, V; PURA, M; VAN-RIEL, A. Customer royalty to content-based websites: the case of an on-line health-care service. Journal of Services Marketing, v. 18, n. 3, p. 175-186, 2004.

HACKMAN, D; GUNDERGAN, S. P; WANG, P; DANIEL, K. A service perspective on modeling intentions of on-line purchasing. Journal of Services Marketing, v. 20, n. 7, p. 459-471, 2006.

HARRIS, L. C; GOODE, M. M. H. The four levels of loyalty and the pivotal role of trust: a study of online service dynamics. Journal of Retailing, v. 80, n. 1, p. 138-158, 2004.

HENNING-THURAU, T; GWINNER, K. P; GREMLER, D. D Understanding relationship marketing outcomes: an integration of relational benefits and relationship quality. Journal of Service Research, v. 5 , n. 2, p. 230-247, 2002.

HENNING-THURAU, T; KLEE, A. The impact of customer satisfaction and relationship quality on customer retention: a critical reassessment and model development. Psychology and Marketing, v. 14, n. 8, p. $737-$ $764,1997$.

HERNANDEZ, J. M. Entendendo melhor o processo de decisão de compra na internet: uma análise sobre o papel da confiança em diferentes. In: ENCONTRO NACIONAL DA ASSOCIAÇÃO NACIONAL DOS PROGRAMAS DE PÓSGRADUAÇÃO EM ADMINISTRAÇÃO, 26, 2002, Salvador. Anais. Salvador: ANPAD, 2002.

KIM, K; FRAZIER, G. L. On distributor commitment in industrial channels of distribution: a multicomponent approach. Psychology and Marketing, v. 14, n. 1, p. 847-877, 1997.

MARCHETTI, R. Z; PRADO, P. M. H. Um tour pelas medidas de satisfação do consumidor. RAE-revista de administração de empresas, v. 4l, n. 4 , p. $56-67,2001$

MATOS, C. A, ROSSI, C. A. V, VEIGA, R. T., VIEIRA, V.A. Consumer reaction to service failure and recovery - the moderating role of attitude toward complaining. Journal of Services Marketing, v.23, n. 7, p. 462-475, 2009. 
MORGAN, R. M; HUNT, S. D. The commitment-trust theory of relationship marketing. Journal of Marketing, v. 58, n. 3, p. 20-38, 1994.

OLIVER, R. L. Whence consumer loyalty? Journal of Marketing, v. 63, Special Issue, p. 33-44, 1999.

PARASURAMAN, A; BERRY, L. L; ZEITHAML, V. Refinement and reassessment of the ServQual scale. Journal of Retailing, v. 67, n. 4, p. 420450,1991

PARASURAMAN, A; GREWAL, D. The impact of technology on the qualityvalue-loyalty chain: a research agenda. Journal of the Academy of Marketing Science, v. 28, n. 1, p. 168-174, 2000.

PARASURAMAN, A; ZEITHAML, V; BERRY, L. L. A conceptual model of service quality and its implications for future research. Journal of Marketing, v. 49, n. 2, p. 41-50, 1985.

PARASURAMAN, A; ZEITHAML, V; BERRY, L. L. ServQual: a multipleitem scale for measuring consumer perceptions of service quality. Journal of Retailing, v. 64, n. 1, p. 12-40, 1988.

PARASURAMAN, A; ZEITHAML, V; MALHOTRA, A. E-S-Qual a multipleitem scale for assessing electronic service quality. Journal of Service Research, v. 7 , n. 3, p. 213-233, 2005.

PRADO, P. H. M; SANTOS, R. C. Intensidade do relacionamento e venda cruzada de produtos: um estudo em bancos de varejo aplicando modelos de traço latente. In: ENCONTRO DE MARKETING DA ASSOCIAÇÃO NACIONAL DOS PROGRAMAS DE PÓS-GRADUAÇÃOEM ADMINISTRAÇÃO, 2, 2006, Rio de Janeiro. Anais. Rio de Janeiro: ANPAD, 2006
SHARMA, N; PATTERSON, P. G. The impact of communication effectiveness and service quality on relationship commitment in consumer, professional services. Journal of Services Marketing, v.13, n. 2/3, p. 151-170, 1999.

VALLE, J. D. Roubo de senhas teve alta de $400 \%$ em 2008. Info Online. Disponível em http://info.abril.com.br/noticias/seguranca/roubode-senhas-teve-alta-de-400-em-2008-24092009-30.shl. Acessado em 01.12.2009.

VIEIRA, V. A; BAPTISTA, P. P. Proposta de uma escala para mensurar comprometimento no varejo eletrônico. In: Varejo competitivo, v. 12, 12. ed., p. 58-83. São Paulo: Saint Paul, 2007.

VIEIRA, V. A. Verificação da e-TailQ como instrumento para mensurar a qualidade no varejo eletrônico. RAE-revista de administração de empresas, v. 48, n. 4 , p. $20-33,2008$

VIEIRA, V. A. An extended theoretical model of fashion clothing involvement. Journal of Fashion Marketing Management, v. 13, n. 2, p. 179-200 2009.

WETZELS, M; RUYTER, K; BIRGELEN, M. V. Marketing services relationship: the role of commitment. Journal of Business and Industrial Marketing, v. 13, n. 4/5, p. 406-423, 1998.

ZEITHAML, V. Defining and relating price, perceived quality, and perceived value. Cambridge, MA: MSI, 1987.

ZEITHAML, V; BERRY, L. L; PARASURAMAN, A. The behavioral consequences of service quality. Journal of Marketing, v. 60, n. 2, p. 31-47, 1996

ZWICK, W. R; VELICER, W. F. Comparison of five rules of determining the number of components to retain. Psychological Bulletin, v. 99, n. 3, p. 432-442, 1986 